Published by LPMP Imperium

Journal homepage: https:/ / ejournal.imperiuminstitute.org/ index.php/JMSAB

\title{
Pengaruh Kepemimpinan Transformasional Dan Kompetensi Terhadap Kinerja Karyawan
}

\author{
Dyah Agustin Widhi Yanti*, Mursidi \\ Program Diploma Pelayaran, Universitas Hang Tuah \\ Surabaya, Indonesia
}

\begin{abstract}
Running a business requires accuracy and speed from the operational process to the process of delivering goods to consumers. This development is supported by the ease of delivery of goods, both from producers to consumers. Goods can be shipped by land, sea, and air shipping. This is a business opportunity for business people who have a strategic location for the delivery route. This study uses a quantitative approach, by collecting data through surveys. Transformational leadership has a significant effect on the performance of employees of PT. Surabaya Container Terminal. Transformational Leadership of PT. The strong Surabaya Container Terminal will have an impact on employee performance. This is due to the application of idealized influence, the behavior of a leader that makes his followers admire, respect and trust him. Competency results have a significant effect on the performance of employees of PT. Surabaya Container Terminal. This means that competence can improve employee performance.
\end{abstract}

\section{Keywords:}

Transformational Leadership, Competencies, Employee Performance.

\section{Corresponding Author:}

Dyah Agustin Widhi Yanti, Program Diploma Pelayaran, Universitas Hang Tuah, Surabaya, Indonesia

Email: rumanintyalisariaputri@gmail.com

(C) The Author(s) 2021

DOI: https:/ / doi.org/ 10.36407/jmsab.v4i1.266

\section{(c) (2)}

CC BY: This license allows reusers to distribute, remix, adapt, and build upon the material in any medium or format, so long as attribution is given to the creator. The license allows for commercial use.

\section{Research Paper \\ Management}

Received: 25 Sep 2020

Revised: 20 Dec 2020

Accepted: 05 Jan 2021

Online: 18Jan 2021

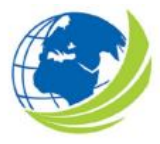

Jurnal Manajemen Strategi dan Aplikasi Bisnis, Vol 4, No. 1, 2021, pp. 23 - 34

eISSN 2655-237X 


\section{PENDAHULUAN}

Pada era globalisasi saat ini, perkembangan bisnis nasional atau internasional sangat pesat. Dalam menjalankan sebuah bisnis dibutuhkan ketepatan dan kecepatan pada proses operasional sampai pada proses pengiriman barang ke konsumen. Perkembangan ini didukung dengan adanya kemudahan pengiriman barang, baik dari produsen ke konsumen. Pengiriman barang dapat melalui jalur darat, jalur laut dan juga jalur udara. Jalur pengiriman barang ini menjadi jalur yang sangat strategis bagi pelaku usaha yang berkecimpung menggunakan jalur ini. Indonesia memiliki lokasi yang strategis sebagai jalur perdagangan baik nasional maupun internasional. Surabaya menjadi salah satu dari beberapa lokasi yang strategis dengan jalur perdagangan, sebab Surabaya memiliki menjadi penghubung antara ketiga jalur perdangan karena disana terdapat pelabuhan yang dijadikan sebagai pelabuhan perdagangan. Selain itu juga ada tol Surabaya dan juga ada jalur kereta api. Maka dari itu Surabaya dapat mempermudah arus pengiriman barang.

PT. Terminal Petikemas Surabaya (TPS) merupakan salah satu perusahaan yang bidangnya ialah pengiriman barang. PT. Terminal Petikemas Surabaya ini menjadi anak perusahaan yang masuk dalam Pelindo III Group. Tahun 1992 merupakan tahun berdirinya Pelindo III Group III. PT. Terminal Petikemas Surabaya (TPS) merupakan perusahaan yang bergerak dalam bidang jasa pelabuhan didalam pelayaran terminal petikemas yang melayani perdagangan dalam dan laur negeri. Apabila dilihat dalam peta geografis maka PT. Terminal Petikemas Surabaya (TPS) terletak di bagian barat pelabuhan Tanjung Perak dengan koordinat 7;12;S, 112;40E, di bagian ujung alur pelayaran di antara pulau Jawa dengan pulau Madura sepanjang 25mil. Dalam rencana kerja tahun 2015-2020 PT. Terminal Petikemas Surabaya memiliki target adanya produksi yang mengalami kenaikan. Pencapaian dapat terjadi dengan cara melakukan dorongan kinerja karyawan yang lebih baik. Ketika kinerja karyawan mengalami kenaikan kualitas maka dapat dikatan tujuan dari perusahaan ini akan tercapai.

Mathis dan Jackson (2015) menyatakan bahwa kinerja karyawan mendapatkan pengaruh dari kemampuan, motivasi, dan juga support, serta adanya hubungan yang terjadi di organisasi. Beberapa faktor yang dapat mempengaruhi kinerja dapat dikelompokkan menjadi dua, yaitu faktor internal seperti kompetensi dan motivasi, dan faktor eksternal seperti budaya, kepemimpinan, teknologi , dan lainnya (Robbins \& Judge, 2019). Dari sisi eksternal, kepemimpinan tranformasional merupakan faktor yang paling banyak mendapatkan perhatian meskipun hubungannya dengan kinerja bukanlah sebuah hubungan yang sederhana. Sebagai contoh, Kearney (2008) menemukan bahwa hubungan kepemimpinan transformasional dengan kinerja dimoderasi oleh perbedaan usia antara pemimpin dan karyawan. Studi lebih baru dilakukan oleh Li et al. (2017) menemukan bahwa stimulasi intelektual memiliki ukuran efek relatif tertinggi pada kinerja, sementara dukungan individual hanya memberikan pengaruh tidak langsung. Selain itu, efek langsung dari ekspektasi kinerja tinggi menjadikan efek totalnya tidak signifikan. Secara umum, Li et al. (2017) menemukan bahwa efek langsung, tidak langsung, dan total dari perilaku transformasional tidak signifikan. Hasil tersebut berbeda dengan temuan Nguyen et al. (2017) yang berhasil menemukan efek signifikan kepemimpinan transformasional terhadap kinerja manajerial di Vietnam. Mendukung studi Nguyen et al. (2017), penelitian ini berupaya untuk melakukan pengujian ulang pada hubungan kepemimpinan transformasional dengan kinerja pada konteks budaya Indonesia. Penelitian ini juga menambahkan faktor kompetensi sebagai pembanding, dimana kepemimpinan 
diasumsikan memiliki efek positif dan didukung oleh kompetensi dari sisi internal akan sama-sama memiliki pengaruh yang signifikan terhadap kinerja.

\section{KAJIAN PUSTAKA}

\section{Kinerja Karyawan}

Mangkunegara (2005:25) menyatakan bahwa kinerja adalah kemampuan kerja yang ditunjukkan dengan hasil kerja yang dibedakan menjadi dua, yaitu kinerja individu dan Kinerja Karyawan. Kinerja sebagai prestasi kerja yakni perbandingan antara hasil kerja yang secara nyata dengan standar kerja yang ditetapkan (Dessler, 2009). Mathis dan Jackson (2006:78) menyatakan bahwa kinerja pada dasarnya apa yang dilakukan atau tidak dilakukan karyawan atau kelompok karyawan. Atmosoeprapto (2001:58), menyatakan bahwa kinerja adalah perbandingan antara keluaran (ouput) yang dicapai dengan masukan (input) yang diberikan. Berdasarkan uraian tersebut dapat sisimpulkan bahwa Kinerja Karyawan adalah pertastasi kerja berupa output dan outcome yang dicapai dalam kurun waktu tertentu dengan pemanfaatan input secara efisien dan efektif yang dicapai melalui pelaksanaan fungsi seluruh personil organisasi.

Ruky (2002) menyatakan bahwa penilaian terhadap Kinerja Karyawan merupakan kegiatan membandingkan antara hasil yang sebenarnya diperoleh dengan yang direncanakan. Gibson et al. (2008), menyatakan bahwa ada tiga perangkat variabel yang mempengaruhi perilaku dan kinerja, yaitu variabel individual, variabel organisasional, dan variabel psikologis. Gibson et al. (2008), Kinerja Karyawan tergantung dari kinerja individu, karena kinerja individu adalah dasar Kinerja Karyawan. Malthis \& Jakson (2015) menyatakan bahwa faktor-faktor yang mempengaruhi kinerja karyawan yaitu bakat, pendidikan, pelatihan, lingkungan dan fasilitas, iklim kerja, gaji, bonus, interseleksi, motivasi, dan kemampuan hubungan industrial, teknologi manajemen, kesempatan berprestasi, dan keberadaan pekerjaan yang mereka lakukan.

\section{Kepemimpinan Transformasional dan Knerja}

Robbins dan Judge (2008:387) menyampaikan bahwa perubahan dari kepemimpinan ialah seorang leader menyamoaikan adanya pertimbangan dan juga melakukan suntikan keilmuan dengan individu yang memiliki kharisma. Bass dan Avolio (1994:203), bahwa untuk menghasilkan produktivitas, kepemimpinan transformasional mempengaruhi organisasi agar tercipta tujuan melalui perilaku. Bass (1990:21) menyatakan bahwa:

"Transformational leadership-occurs when leaders broaden and elevate the interests of their employees, when they generate awareness and acceptarice of the purposes and mission of the group, and when they stirs their employees to look beyond their own self-interest for the good of the group" (Kepemimpinan terjadi ketika para pemimpin memperluas dan meningkatkan kepentingan karyawan, membangkitkan kesadaran menerima tujuan dan misi kelompok, dan membangkitkan karyawan melampaui kepentingan sendiri untuk kebaikan kelompok)"

Kepemimpinan transformasional berpengaruh terhadap kinerja Karyawan sebagaimana temuanpenelitian Orabi, (2016:89-102), dengan judul The impact of transformational leadership style on organizational performance: evidence from Jordan. Hasil penelitian 
menunjukkan ada pengaruh signifikan antara gaya kepemimpinan transformasional dan kinerja Karyawan. Penelitian Laras dan Haryono (2016), Gillet dan Vandenberghe (2014) menemukan pengaruh signifikan positif antara kepemimpinan transformasional dengan kinerja Karyawan.

$\mathrm{H}_{1}$ : kepemimpinan transformasional berpengaruh signifikan terhadap kinerja

\section{Kompetensi dan Kinerja}

Kompetensi ialah kemampuan dari seseorang yang menjadikan ciri mereka atau dapat dikatakan sebagai keahlian yang dimiliki oleh seseorang (Noe et.al 2011:351). Rivai (2003:298) menyatakan bahwa kompetensi adalah kecakapan, keterampilan, kemampuan. Roe (2001:73) menyatakan bahwa: "Competence is defined as the ability to adequately perform a task, duty or role; competence integrates knowledge, skills, personal values and attitudes; competence builds on knowledge and skills and is acquired through work experience and learning by doing". (Kompetensi didefinisikan sebagai kemampuan untuk secara memadai melakukan tugas, tugas atau peran; kompetensi mengintegrasikan pengetahuan, keterampilan, nilai-nilai pribadi dan sikap; kompetensi dibangun berdasarkan pengetahuan dan keterampilan dan diperoleh melalui pengalaman kerja dan dengan melakukan pembelajaran).

Robbin dan Judge (2019) menyampaikan bahwa kemampuan merupakan kapasitis seseornag yang handal dalam bidang tertentu. Sedarmayanti (2008:1) menyatakan kompetensi adalah karakteristik mendasar yang dimiliki seseorang yang berpengaruh langsung, atau dapat memprediksikan kinerja yang sangat baik. Kompetensi merupakan kemampuan yang dibutuhkan yang dapat mempengaruhi Kinerja Karyawan. Penelitian Osei (2015) menemukan bahwakompetensi karyawan berpengaruh positif terhadap kinerja karyawan, dan Zaim et.al (2013) yang juga berhasil mengkonfirmasi hubungan tersebut Studi di dalam negeri antara lain oleh Rantesalu et al. (2016), Yunus dan Muhajar (2014); Faisal (2016); Sriekaningsih dan Setyadi (2015) juga berhasil membuktikan ada pengaruh kompetensi dalam meningkatkan kinerja karyawan.

\section{$\mathrm{H}_{2}$ : kompetensi berpengaruh signifikan terhadap kinerja}

\section{METODE PENELITIAN}

Penelitian ini merupakan penelitian penjelasan karena bermaksud untuk menjelaskan pengaruh antar variabel melalui pengujian hipotesis dan melakukan eksplanasi terhadap beberapa variabel, maka sifat penelitian ini adalah penelitian eksplanasi (Explanation Research). Peneliti akan melakukan penelitian pengaruh variabel bebas (Independent Variable) yaitu variabel Kepemimpinan Transformasional dan Kompetensi terhadap Kinerja Karyawan (variabel terikat). Penelitian ini menggunakan pendekatan kuantitatif, dengan cara mengumpulkan data melalui survey. Survey yang dilakukan pada Terminal Peti Kemas Surabaya, sebagai sebuah terminal berstandar kelas dunia di Indonesia, dengan menyampaikan daftar pertanyaan kepada responden terpilih. Sebagai responden dalam penelitian ini adalah karyawan pada Terminal Ptikemas Surabaya. Data yang digunakan dalam penelitian ini terdapat dua sumber yaitu; data primer. Data primer diperoleh dengan cara menyebarkan kuesioner kepada Karyawan yang bekerja di Terminal Petikemas Surabaya. 


\section{Populasi Penelitian}

Penelitian ini dilakukan pada kota metropolitan terbesar di Jawa Timur yaitu Kota Surabaya. Penelitian difokuskan pada karyawan Terminal Petikemas Suarabaya. Populasi dalam penelitian ini adalah seluruh pelabuhan yang dikelola PT Pelabuhan Indonesia III dengan menggunakan 43 pelabuhan umum. Dengan karyawan yang berjumlah 378. Populasi dalam penelitian ini adalah karyawan Terminal Petikemas Suarabaya.

\section{Sampel Penelitian}

Menurut Emory (2005:87) untuk metode deskriptif sampel minimum 10\% populasi dan untuk populasi yang relatif kecil sampel yang dapat diterima minimal $20 \%$ populasi. Dari beberapa metode yang ada, untuk pemilihan sampel yang dikemukakan para ahli, pada penelitian ini menarik sampel dengan menggunakan metode proporsional random sampling (teknik sampel proporsional). Selanjutnya berdasarkan dari penjelasan tersebut, jumlah sampel dalam penelitian ini ditentukan sebanyak 378 x 20\% = 76 karyawan.

\section{Pengukuran}

Untuk mengukur data yang dibutuhkan, skala likert digunakan dalam penelitian ini. Skala Likert dengan interval 1 s.d 5, menanyakan respon individu terhadap beberapa pernyataan yang mengindikasikan seseorang Strongly Agree (SA), Agree (A), Undecided (U), Disagree (D) atau Strongly Disagree (SD) dengan pernyataan tersebut.

Kinerja diukur berdasarkan sebelas indikator dari Bernardin dan Russel (2003:383) meliputi:

1. Responsivitas, kemampuan mengenali kebutuhan, harapan, keinginan, aspirasi serta tuntutan masyarakat

2. Responsibilitas, kesesuaian penyelenggaraan pemerintah dengan peraturan dan prosedur yang telah ditetapkan

3. Akuntabilitas, kesesuaian antara penyelenggaraan pemerintahan dengan ukuran eksternal di masyarakat seperti nilai dan norma yang berkembang dalam masyarakat

4. Keadaptasian, daya tanggap organisasi terhadap tuntutan perubahan yang terjadi dilingkungannya

5. Kesinambungan, kemampuan pelayanan yang terus berkembang dan berkesinambungan

6. Transparansi, terbukaan penyelenggaraan pemerintahan dan proses pelayanan yang wajib diinformasikan secara terbuka

7. Empati, tingkat perhatian pemerintah daerah terhadap isu-isu kebutuhan masyarakat

8. Kualitas, tingkat keberhasilan pelaksanaan kegiatan mendekati kesempurnaan atau mendekati tujuan yang diharapkan sesuai jumlah unit yang dihasilkan berdasarkan target

9. Proporsionalitas, mengutamakan keseimbangan antara hak dan kewajiban penyelenggaraan Pemerintahan Desa

10. Profesionalitas, ukuran pelaksanaan tugas mengutamakan keahlian berlandaskan kode etik, kegiatan diselesaikan waktu dengan memperhatikan output dan waktu yang tersedia

11. Keefektifan biaya, tingkat penggunaan sumberdaya organisasi (manusia, keuangan, teknologi, material) yang dimaksimalkan untuk mencapai hasil tertinggi dari setiap unit penggunaan sumberdaya. 
Kepemimpinan transformasional diukur berdasarkan empat dimensi menurut Bass dan Riggio (2006; 6-7), kepemimpinan transformasional dalam teorinya dapat dilihat empat komponen inti selalu melekat atau lebih dikenal dengan 4-I yaitu: (1) idealized influence, tingkah laku pemimpin yang diikuti secara tidak disadari oleh pengikutnya; (2) inspirational motivation, pemimpin yang menjadi penyemangat dan juga memberikan lamgkah dan harapan baru bagi pengikutnya; (3) intellectual stimulation, pemimpin yang selalu memiliki ide baru yangdapat di contoh oleh bawahannya.; dan (4) Individualized consideration, pemimpin yang bertipe pendengar yang setia sehingga keluh kesah bawahan didengarkan dengan baik.

Kompetensi di ukur mengacu dimensi yang dikembangkan oleh Spencer dan Spencer (1993:9-11) yaitu: (1) Motives, hal yang dipikirkan seseorang yang menyebabkan tindakan yang dijabarkan dalam indikator dorongan kebutuhan ekonomi, kebutuhan sosial, dan kebutuhan psikologis. (2) Traits, karakteristik fisik dan respon konsisten terhadap situasi informasi yang dijabarkan dalam indikator watak, sifat, dan sikap. (3) Self-concept, atitude, nilai, atau citra diri seseorang yang dijabarkan dalam indikator penampilan, tutur bahasa dan perilaku. (4) Knowledge, informasi yang dimiliki seseorang pada konten area tertentu yang dijabarkan dalam indikator pengetahuan tentang prosedur pelayanan dan teknis pelayanan. (5) Skills, kemampuan untuk melakukan tugas fisik atau mengandung mental yang dijabarkan dalam indikator keterampilan administratif, manajerial, teknis, dan social.

\section{Teknik Pengambilan dan Pengumpulan Data}

Data yang dikumpulkan dalam penelitian ini meliputi dua jenis, yakni data primer dan data sekunder. Data primer berasal dari responden, diperlukan untuk menguji hipotesis yang telah ditetapkan. Sedangkan data sekunder berasal dari masing-masing unit pasar. Teknik yang dipergunakan dalam mengumpulkan data dalam penelitian ini adalah teknik survey dengan instrumen kuesioner, yaitu membuat daftar pernyataan yang berhubungan dengan variabel penelitian ini, kemudian dibagikan kepada seluruh responden yang dijadikan sasaran penelitian atau dilakukan wawancara untuk menjawab pernyataan dalam kuesioner.

\section{Analisis Data Regresi Linier Berganda}

Analisis regresi linear berganda merupakan analisis yang bertujuan untuk menganalisa pengaruh variabel tidak bebas (variabel dependen) terhadap variabel lainnya yang bebas (variabel independen). Analisis regresi linier berganda digunakan karena peneliti ingin mengetahui pengaruh beberapa variabel bebas terhadap variabel tidak bebas berdasarkan pengembangan secara profesional.

\section{HASIL DAN PEMBAHASAN}

\section{Analisis Deskriptif}

Hasil analisis diskriptif tentang kinerja karyawan PT. Terminal Petikemas Surabaya telah di respons oleh karyawan PT. Terminal Petikemas Surabaya yang menjadi responden dalam penelitian ini dengan nilai rata-rata sebesar 4.517, ini berarti bahwa butir-butir pernyataan yang diajukan tentang Kinerja karyawan PT. Terminal Petikemas Surabaya telah diakui oleh mereka dalam kategori Sangat Tinggi, hal ini mengindikasikan bahwa karyawan PT. Terminal Petikemas Surabaya telah mencapai kinerja dengan kategori sangat baik. Berdasarkan unsur 
yang mempengaruhi kinerja karyawan PT. Terminal Petikemas Surabaya yaitu kuantitas kerja karyawan sangat tinggi, artinya karyawan mampu menyelesaikan sejumlah aktivitas yang ditugaskan, karyawan mampu bekerja sesuai dengan target, karyawan mampu menyelesaikan pekerjaan sesuai dengan kurun waktu yang ditentukan, kecepatan menyelesaikan pekerjaan serta karyawan memiliki perilaku disiplin yang tinggi pada pekerjaan.

Unsur kualitas juga dinyatakan sangat tinggi, artinya hasil pekerjaan memenuhi standar kualitas yang ditentukan, rendahnya kesalahan dalam melakukan pekerjaan, tidak adanya kecelakaan kerja di lingkungan kerja, ketaatan karyawan terhadap prosedur kerja sangat tinggi, karyawan mampu memenuhi tujuan-tujuan yang diharapkan dari suatu pekerjaan serta karyawan memiliki ketrampilan dalam menyelesaikan pekerjaan.

Unsur keandalan dinyatakan sangat tinggi, artinya karyawan memperhatikan keselamatan dalam menjalankan pekerjaan, karyawan memiliki kemampuan untuk melakukan pekerjaan yang disyaratkan, konsistensi dalam penyelesaian pekerjaan serta memiliki tingkat ketaatan pada semua aturan dan prosedur kerja yang ditetapkan oleh organisasi.

Unsur kehadiran dinyatakan sangat tinggi, artinya pada saat menjalankan tugas di lingkungan PT. Terminal Petikemas Surabaya kehadiran karyawan selalu tepat waktu, seluruh tugas dapat diselesaikan dengan tepat waktu, kehadiran karyawan pada saat mendapat tugas untuk mengikuti kegiatan di PT. Terminal Petikemas Surabaya, tidak menunda pekerjaan, disiplin terhadap jam kerja, serta selalu hadir sesuai dengan jadwal kerja.

Unsur kemampuan bekerja sama dinyatakan sangat baik, artinya karyawan mampu untuk bekerja bersama dengan karyawan lain, karyawan mampu dalam menyelesaikan suatu tugas pekerjaan dengan karyawan lain, tanggung jawab secara bersama-sama dalam menyelesaikan pekerjaan, saling berkontribusi untuk menyelesaikan pekerjaan serta adanya pengerahan kemampuan masing-masing anggota tim secara maksimal.

\section{Analisis Regresi}

Berdasarkan dari hasil perhitungan pengelolahan data dengan program SPSS 17.00 maka diperoleh persamaan regresi linier berganda pada tabel 1. Uji kecocokan model (gooness of fit) dengan uji $F$ menunjukkan bahwa nilai $F_{\text {hitung }} 250,081 \geq F_{\text {tabel }} 2.57$, sehingga secara dapat dinyatakan model sudah memiliki kecocokan model yang baik sehingga dapat diinterpretasi lebih lanjut.

\section{Tabel 1.}

Analisis Regresi

\begin{tabular}{lrrrr}
\hline & Koefisien & SE & t & sig \\
\hline (Constant) & 6,787 & 1,957 & 3,468 &, 001 \\
X1 &, 325 &, 154 & 2,114 &, 038 \\
X2 &, 689 &, 132 & 5,205 &, 000 \\
R_square & & & & \\
F-Statistics & 250,081 & & & \\
\hline
\end{tabular}

Bentuk persamaan regresi tersebut adalah sebagai berikut : 
$\mathrm{Y}=6,787+0.325 \mathrm{X} 1+0.689+\mathrm{e}$

\section{Uji Hipotesis}

Untuk menguji hipotesis digunakan uji t yang menunjukkan pengaruh secara parsial dari masing-masing variabel bebas terhadap variabel terikat. Pada tahapan ini dilakukan pengujian terhadap pengaruh variabel bebas tang terdapat pada model yang terbentuk untuk mengetahui apakah variabel bebas (X) yang ada pada model secara parsial mempunyai pengaruh yang signifikan terhadap variabel terikat (Y). Berdassarkan tabel 1 dapat diketahui pengaruh masing-masing variabel secara parsial sebagai berikut :

Kepemimpinan Transformasional berdasarkan perhitungan diperoleh $t_{\text {hitung }}$ sebesar 2,114>t tabel 1.993 dengan tingkat signifikansi sebesar $0.000<0.05$ ). karena $t_{\text {hitung }}$ lebih besar dari ttabel, maka $\mathrm{H}_{1}$ diterima artinya Kepemimpinan Transformasional berpengaruh signifikan terhadap kinerja karyawan. Kompetensi berdasarkan perhitungan diperoleh $t_{\text {hitung }}$ sebesar $5,205>t_{\text {tabel }} 1.993$ dengan tingkat signifikansi sebesar $0.000<0.05$ ). karena $t_{\text {hitung }}$ lebih besar dari $\mathrm{t}_{\text {tabel, }}$ maka $\mathrm{H}_{2}$ diterima artinya Kompetensi berpengaruh signifikan terhadap kinerja karyawan.

\section{Pembahasan}

Kepemimpinan transformasional terbukti signifikan mempengaruhi kinerja karyawan. Hal ini menunjukkan bahwa tercapai tidaknya tujuan organisai sangat ditentukan oleh perilaku dan kemampuan pimpinan organisasi yang merupakan faktor utama dalam membangun etos kerja dalam organisasi Bass dan Avolio (2004:294). Seperti halnya yang disampaikan oleh Bass, 1985; Bass \& Avolio, 2004; Burns, 1978 bahwa kepemimpinan transformasional lebih proaktif dan lebih efektif dibanding kepemimpian transaksional dalam hal memotivasi bawahan untuk mencapai kinerja yang lebih baik. Teori ini banyak didukung oleh sejumlah temuan-temuan penelitian seperti Avolio (2004), Maabuat (2016), dan Li et al. (2017).

Para pimpinan transformasional lebih mampu dan lebih sensitif merasakan lingkungannya, dan untuk selanjutnya membentuk dan mendiseminasi sasaran-sasaran strategis yang mampu menangkap perhatian serta minat para bawahannya, Bass dan Avolio (2004:297).Para pengikut pimpinan transformasional memperlihatkan tingkat komitmen yang lebih tinggi terhadap misi organisasi, kesediaan untuk bekerja lebih keras, kepercayaan yang lebih tinggi terhadap pimpinan, dan tingkat kohesi yang lebih tinggi, Bass dan Avolio (2004:298). Di lingkungan PT. Terminal Petikemas Surabaya Kepemimpinan transformasional diperlukan untuk memotivasi karyawanya yang selama ini masih memiliki kinerja yang belum optimal.

Hasil penelitian ini juga mendukung beberapa hasil penelitian antara lain hasil penelitian dari Podsakoff, Mackenzie and Bommer (1996), yang menunjukkan bahwa bawahan akan merasa yakin dan respek kepada pemimpinnya yang berperilaku transformasional sehingga termotivasi untuk bekerja lebih daripada yang diharapkan serta hasil penelitian Sosik (1997), yang menyimpulkan bahwa kelompok yang bekerja di bawah bauran kepemimpinan transaksional dan transformasional yang komposisinya lebih di dominasi oleh kepemimpinan transformasional akan menghasilkan tingkat kinerja, uapaya ekstra (extra effort), dan kepuasan (satisfaction with the leader) yang lebih tinggi daripada kelompok yang bekerja di bawah bauran kepemimpinan yang lebih didominasi oleh kepemimpinan transaksional. Hasil penelitian ini juga mendukung hasil penelitian Suharto 
(2005) dimana salah satu hasil penelitianya menunjukkan bahwa Kepemimpinan transformasional berpengaruh langsung, positif dan signifikan terhadap kinerja bawahan.

Kompetensi berpengaruh positif terhadap kinerja pemerintah desa sehingga pengaruhnya makin besar apabila indikator yang nilai pengaruhnya rendah terendah pada indikator traits, terkait dengan watak, sifat, dan sikap dapat meningkatkan pengaruhnya pada indikatorkinerja kualitas. Mangkunegara (2005:25) menyatakan bahwa kinerja adalah kemampuan kerja yang ditunjukkan dengan hasil kerja yang dibedakan menjadi dua, yaitu kinerja individu dan kinerja organisasi.Kinerja individu adalah hasil kerja karyawan baik kualitas maupun kuantitas berdasarkan standar kerja yang telah ditentukan, sedangkan kinerja organisasi adalah gabungan dari kinerja individu dengan kinerja kelompok. Penelitian ini mendukung hasil penelitian Penelitian Osei (2015), Zaim et.al (2013) Rantesalu et al. (2016), Yunus dan Muhajar (2014) dan Faisal (2016); Sriekaningsih dan Setyadi (2015).

\section{KESIMPULAN}

Penelitian ini ditujukan untuk menguji pengaruh kepemimpinan transformasional dan kompetensi terhadap kinerja karyawan. Hasil studi menunjukkan bahwa epemimpinan transformasional dan kompetensi terbukti berpengaruh signifikan terhadap kinerja karyawan PT. Terminal Petikemas Surabaya.

Kepemimpinan Transformasional PT. Terminal Petikemas Surabaya yang kuat akan membawa dampak terhadap kinerja karyawan. Hal ini dikarenakan dengan penerapan Idealized influence, perilaku pemimpin yang membuat pengikutnya mengagumi, menghormati dan mempercayainya. Inspirational motivation, pemimpin mengartikulasikan pengharapan dengan jelas prestasi bawahan, mendemonstrasikan komitmennya terhadap tujuan organisasi, dan mampu menggugah spirit tim dalam organisasi melalui penumbuhan antusiasme dan optimisme. Intellectual stimulation, pemimpin mampu menumbuhkan ideide baru, memberikan solusi kreatif terhadap permasalahan dan memberikan motivasi bawahan untuk mencari pendekatan baru dalam melaksanakan tugas organisasi. Individualized consideration, pemimpin mau mendengarkan dengan penuh perhatian masukan-masukan dan secara khusus memperhatikan kebutuhan bawahan akan

pengembangan karier. Perusahaan perlu melakukan pelatihan kepemimpinan kepada karyawan di level supervisor dan manager untuk meningakatkan empat komponen kepemimpinan transformasional tersebut.

Selanjutnya, kompetensi berpengaruh signifikan terhadap kinerja karyawan PT. Terminal Petikemas Surabaya. Artinya Kompetensi dapat meningkatkan kinerja karyawan. Peningkatan kinerja karyawan ini disebabkan karena adanya sikap kepedulian pihak manajemen PT. Pelindo III Provinsi Jawa Timur. Upaya untuk meningkatkan kompetensi karyawan dapat dilakukan dengan melaksanakan kegiatan pelatihan secara berkala untuk memperkuat motif, skill, dan pengetahuan sehingga kebutuhan akan ketertampilan tertentu tetap dapat dipenuhi mengikuti perkembangan zaman.

\section{Keterbatsan dan Agenda Penelitian Mendatang}

Studi ini dilakukan pada satu perusahaan sehingga memiliki keterbtasan pada generalisasi hasil. Selain itu, pengambilan data menggunakan desain cross-sectional memiliki kelemahan pada klaim kausalitas hubungan antar variabel. Dengan demikian, studi selanjutnya dapat memperluas area penelitian dan pengambilan sampel yang lebih besar pada beberapa 
peusahaan untuk meningkatkan generalisasi hasil. Penelitian mendatang juga perlu mempertimbangkan penggunakan desain longitudinal untuk memperkuat klaim hubungan sebab akibat antar variabel.

\section{REFERENSI}

Atmosoeprapto, K. (2001). Produktivitas Aktualisasi Budaya Perusahaan: Mewujudkan Organisasi yang Efektif dan Efisien Melalui SDM Berdaya. PT Elex Media Komputindo. Jakarta.

Avolio, B. J., Bass, B. M., \& Jung, D. I. (1999). Re-examining the components of transformational and transactional leadership using the Multifactor Leadership.Journal of occupational and organizational psychology, 72(4), 441-462.

Avolio, B. J., Zhu, W., Koh, W., \& Bhatia, P. (2004). Transformational leadership and organizational commitment: Mediating role of psychological empowerment and moderating role of structural distance. Journal of Organizational Behavior: The International Journal of Industrial, Occupational and Organizational Psychology and Behavior, 25(8), 951-968.http:/ / dx.doi.org/ 10.1002/ job.283.

Bass, B. M., \& Riggio, R. E. (2006). Transformational leadership. Psychology press.

Bass, B. M. (1990). From transactional to transformational leadership: Learning to share the vision. Organizational dynamics, 18(3), 19-31.

Burns, J.M.G. (1978). Leadership. New York: Harper dan Row Publishers

Faisal, M., (2016). Effect of Competence, Leadership and Organizational Culture Toward Organization Commitment and Performance of Civil Servants on the Regional Office of Ministry of Religious Affairs in the Province of the West Sulawesi, 1-16. Available at SSRN: https:// ssrn.com/abstract $=2888812$

Gibson, J. L., Ivancevich, J. M., \& Donnely, T. H. (2008). Organisasi dan Manajemen: Perilaku, Struktur, Proses.(Terj). Jakarta: Penerbit Erlangga.

Gillet, N., \& Vandenberghe, C. (2014). Transformational leadership and organizational commitment: The mediating role of job characteristics. Human Resource Development Quarterly, 25(3), 321-347.https:/ / doi.org/ 10.1002/ hrdq. 2119

Kearney, E. (2008). Age differences between leader and followers as a moderator of the relationship between transformational leadership and team performance. Journal of occupational and Organizational Psychology, 81(4), 803-811. https:// doi.org/ 10.1348/096317907X256717

Laras, T., \& Haryono, R. T. (2016). Kepemimpinan Transformasional, Motivasi Dan Budaya Organisasi Dampaknya Terhadap Kinerja Perangkat Desa (Survey Pada Perangkat Desa Kecamatan Temon Kabupaten Kulon Progro Propinsi Daerah Istimewa Yogyakarta). Jurnal Ekonomi, 21(2), 269-289.

Li, J., Furst-Holloway, S., Gales, L., Masterson, S. S., \& Blume, B. D. (2017). Not all transformational leadership behaviors are equal: The impact of followers' identification with leader and modernity on taking charge. Journal of Leadership \& Organizational Studies, 24(3), 318-334. https:// doi.org/10.1177\%2F1548051816683894

Maabuat, E. S. (2016). Pengaruh Kepemimpinan, Orientasi Kerja, dan Budaya Organisasi terhadap Kinerja Pegawai (Studi Pada Dispenda Sulut Uptd Tondano). Jurnal Berkala Ilmiah Efisiensi, 16(1).

Mangkunegara, A. A. P. (2005). Evaluasi kinerja SDM. Tiga Serangkai

Mathis, R. L., Jackson, J. H., \& Valentine, S. R. (2015). Human resource management: Essential perspectives. Cengage Learning.

Nguyen, T. T., Mia, L., Winata, L., \& Chong, V. K. (2017). Effect of transformational-leadership style and management control system on managerial performance. Journal of Business Research, 70, 202-213. https:// doi.org/ 10.1016/j.jbusres.2016.08.018 
Osei-Kyei, R., \& Chan, A. P. (2015). Review of studies on the Critical Success Factors for Public-Private Partnership (PPP) projects from 1990 to 2013. International journal of project management, 33(6), 1335-1346.

Podsakoff, P. M., MacKenzie, S. B., \& Bommer, W. H. (1996). Transformational leader behaviors and substitutes for leadership as determinants of employee satisfaction, commitment, trust, and organizational citizenship behaviors. Journal of management, 22(2), 259-298.

Rantesalu, A., \& Mus, A. R. Mapparenta, \& Arifin, Z.(2016). The effect of competence, motivation and organizational culture on employee performance: The mediating role of organizational commitment. Journal of Reseacrh in Business and Management, 4(9), 814.

Rivai, V., (2003), Manajemen Sumber Daya Manusia untuk Perusahaan: cite in Sedarmayanti. (2008), Manajemen Sumber Daya Manusia, Bandung: PT. Refika Aditama

Robbins, S. P., \& Judge, T. A. (2019). Organizational behavior. Pearson.

Ruky, A. S. (2002). Sistem manajemen kinerja. Gramedia Pustaka Utama

Spencer, L. M. S. (1993). Signe. M. Competence at work, models for superior performance, John Wile\&Sons. Inc, USA.

Sriekaningsih, A., \& Setyadi, D. (2015). The effect of competence and motivation and cultural organization towards organizational commitment and performance on state university lecturers in East Kalimantan Indonesia. European Journal of Business and Management, 7(17), 208-220.

Sosik, J. J., Avolio, B. J., \& Kahai, S. S. (1997). Effects of leadership style and anonymity on group potency and effectiveness in a group decision support system environment. Journal of applied psychology, 82(1), 89.

Suadnyani, D. M. L., \& Netra, I. G. S. K. (2018). Pengaruh Kepemimpinan Transformasional, Motivasi dan Kepuasan Kerja terhadap Komitmen Organisasional. E-Jurnal Manajemen Universitas Udayana, 7(4).

Yukl, G.A. (2005). Kepemimpinan Dalam Organisasi, edisi kelima. Jakata: PT Indeks.

Yunus, J. M., \& Mahajar, A. J. (2014). Contributing Factors To The Turnover Intention Of Medical Employees Of National Heart Institute Kuala Lumpur (IJN). International Business Education Journal, 7, 52-63.

Zaim, H., Yasar, M. F., \& Unal, O. F. (2013). Analyzing The Effects of Individual Competencies on Performance: A Field Study in Services Industries in Turkey. Journal of Global Strategic Management , 14, 67-77. 


\section{Declarations}

\section{Funding}

The authors received no financial support for the research and publication of this article.

\section{Conflicts of interest/ Competing interests:}

The authors have no conflicts of interest to declare that are relevant to the content of this article.

\section{Data, Materials and/ or Code Availability:}

Data sharing is not applicable to this article as no new data were created or analyzed in this study.

\section{How to cite this Article}

Yanti, D. A., \& Mursidi, M. (2021). Pengaruh Kepemimpinan Transformasional Dan Kompetensi Terhadap Kinerja Karyawan. Jurnal Manajemen Strategi Dan Aplikasi Bisnis, 4(1), 23 - 34.

Retrieved from https:// ejournal.imperiuminstitute.org/index.php/JMSAB/ article/view/ 266 